\title{
Diseño e implementación de una plataforma piloto de marketing electrónico para el desarrollo de aplicaciones TICs en la comunidad de Ciudad Bolívar
}

\section{Design and implementation of a pilot platform of electronic marketing for development of icts applications in the community of Ciudad Bolívar}

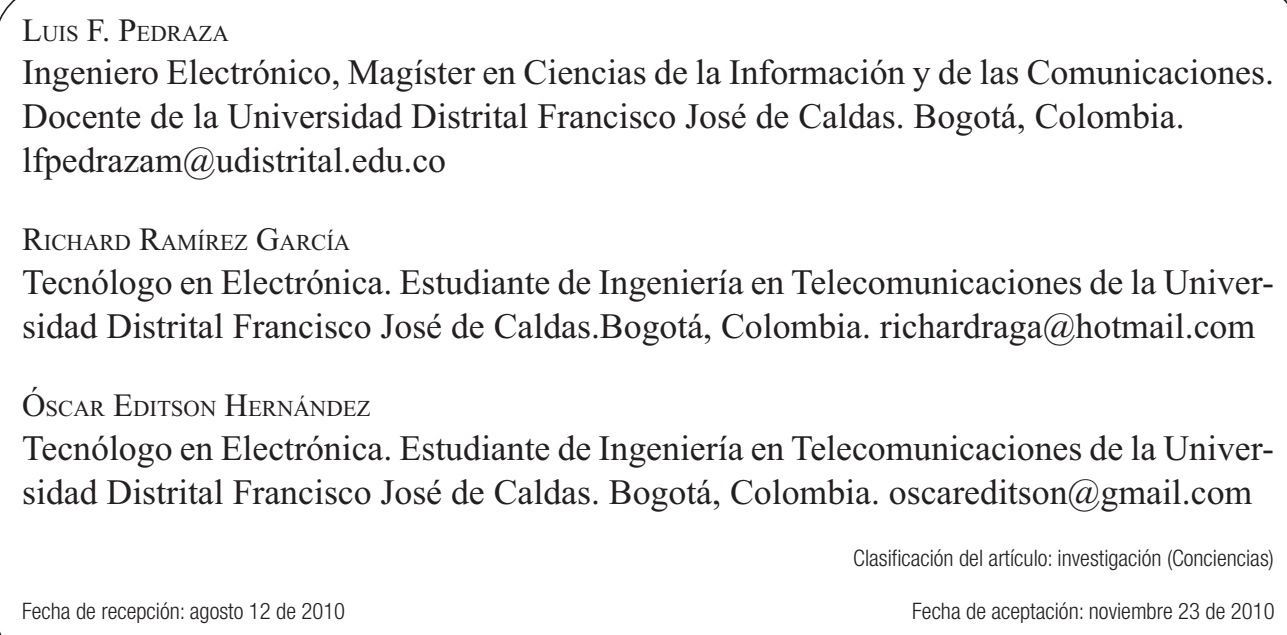

Palabras clave: Gestor de Contenidos, Joomla, Marketing Electrónico, Software libre, TICs.

Key words: Content Management, Joomla, Electronic Marketing, Free software, ICTs.

\section{Resumen}

En este proyecto se presenta el diseño de una plataforma piloto de marketing electrónico dirigido a la comunidad de la localidad de Ciudad Bolívar en Bogotá, Colombia, que permite ofrecer productos y servicios a los habitantes de la localidad y se pretende convertir en una plataforma para su mejoramiento y desarrollo económico, especialmente de las pequeñas y medianas empresas, a partir de la creación de nuevas oportunidades de mercado y nuevos objetivos de negocio.

En este documento se da a conocer un estudio socioeconómico de Ciudad Bolívar que permite ubicarse en el entorno de desarrollo en el que se implementa la herramienta, así como también per- 


\section{con-ciencias}

mite conocer el diseño estructural y de software del aplicativo implementado en un servidor virtual sobre Internet.

La plataforma de marketing electrónico denominada MiMercado está diseñada para ofrecer consultas sobre los productos más económicos de la localidad, ubicación del lugar donde se venden, y la manera de contactar y realizar negocios. El aplicativo diseñado permite a los trabajadores independientes y profesionales ofrecer servicios de una manera interactiva y rápida con el fin de disminuir el desempleo en la localidad y, a su vez, mejorar el acceso a las TICs (Tecnologías de la Información de las Comunicaciones) de las personas del sector.

\section{Abstract}

In this project presents the design of a pilot platform of electronic marketing aimed at the community of Ciudad Bolivar locality in Bogotá Colombia that allow offer products and service store residents of locality and aims to become a platform for improvement and economic development of the same, especially of small and medium enterprises creating new market to opportunities and new business objectives. In this paper shows, a socio-economic study of Ciudad Bolivar locality, that allow to be located in the development environment which above tool is implemented, as well as structural design and application software implemented in a virtual server on Internet.

The platform of electronic marketing called MiMercado is designed to provide consultation on the cheaper products of the locality, location of the place where the product is sold and the way to contact and do business. The designed application allows to self-employed and professionals to offer services one way interactive and quick in order that make a drop in unemployment in the locality and at the same time enabling to improve access to ICTs (Information and Communications Technology) of sector people.

\section{Introducción}

El convenio de Ciudad Bolívar Localidad Digital, bajo el liderazgo de la Universidad Distrital Francisco José de Caldas, realizó, durante el mes de diciembre del año2009, 10000 encuestas a hogares y 1000 encuestas a negocios en la localidad 19 de Ciudad Bolívar, como muestra significativa para una población de 650000 personas aproximadamente.

Según un análisis de estas encuestas, se encontró que hay tres variables fundamentales en la localidad que resaltan las necesidades del sector: pobreza, educación y empleo. Se obtuvo lo siguiente:

- Nivel de pobreza muy alto, el $94 \%$ pertenece al estrato uno y dos. El 5,3\% de los hogares de la localidad se consideran en pobreza por NBI (Necesidades Básicas Insatisfechas). El 0,5\%

se encuentra en condiciones de miseria. El 3,3\% de las familias de Ciudad Bolívar habitan en viviendas cuyas condiciones son inadecuadas. El 7,6\% vive en situaciones de hacinamiento crítico y el $1,7 \%$ tiene inasistencia escolar.

- El porcentaje de analfabetismo es del 4,6\% y ocupa el segundo nivel más alto de las 20 localidades de Bogotá.

- En el 4,5\% de los hogares hay alta dependencia económica [1].

Ciudad Bolívar cuenta con un entorno que ha permitido el desarrollo de actividades de servicios y la creación de un importante centro de comercio. Sus principales actividades productivas son: el comercio de alimentos, víveres en general, bebidas y tabaco; productos farmacéuticos, medicinales y

Diseño e implementación de una plataforma piloto de marketing electrónico para el desarrollo de aplicaciones TICs en la comunidad de Ciudad Bolívar Luis F. Pedraza / Richard Ramirez Garcia / Óscar Editson Hernández 


\section{con-ciencias}

odontológicos; artículos de perfumería, cosméticos y productos de arreglo y aseo personal; artículos de ferretería, cerrajería y productos de vidrio; cacharrerías y misceláneas; fabricación de vestidos, ropa exterior e interior para hombre, niño, mujer y niña, corsetería, camisería; elaboración de productos alimenticios y bebidas; curtido y preparado de cueros, entre otros.

Debido a los problemas expuestos anteriormente y conociendo las actividades comerciales, surge la iniciativa de diseñar e implementar una plataforma piloto de marketing electrónico de fácil operación que permita ofrecer productos y servicios a los habitantes de la localidad y mejorar las condiciones de desarrollo de la comunidad, en especial de las pequeñas y medianas empresas. Algunos desarrollos sobre marketing electrónico fueron:

En [2] se propone un modelo conceptual para la aplicación del comercio electrónico en las PYMES (Pequeñas y Medianas Empresas) en México, lo cual sirve de fundamento para la aplicación diseñada. En [3] se presentan varias aplicaciones que se han usado como soluciones para el fortalecimiento del modelo de negocio de las PYMES, entre éstas se encuentran: una aplicación en Colombia de tienda electrónica para PYMES de zonas vulnerables de Medellín, una plataforma para el sector farmacia en Venezuela (TIC-FAR-VEN) y la implantación de una plataforma de negocios y servicios en Uruguay en 240 farmacias. Estas herramientas de tecnología de la información y las comunicaciones buscan mejorar la integración de las PYME a los mercados globales, mejorar la competitividad de los mercados, promover la innovación en sus prácticas de negocios, gestión comercial y procesos de cooperación.

\section{Desarrollo de la plataforma}

A continuación se explica de manera detallada el estudio de tráfico de datos que puede soportar la plataforma web.

\subsection{Análisis de tráfico}

El alojamiento de la página web está en un servidor que ofrece algunas características como $1 \mathrm{~GB}$ de espacio en disco, $30 \mathrm{~GB}$ de transferencia mensual y un canal dedicado de un E1. Las características de este servicio se modelan como una cola de bloqueo tipo $\mathrm{M} / \mathrm{M} / \mathrm{N} / \mathrm{N}$, debido a que es un servicio de red con un único servidor sin línea de espera, con la posibilidad de albergar $\mathrm{N}$ elementos de red y con capacidad poblacional infinita [4].

Para el análisis de tráfico de un usuario que deseapublicar su información,setiene inicialmente una troncal con un canal aprovisionado de un E1 donde su capacidad C es de $2 \mathrm{Mbps}$ ( $250 \mathrm{KBps})$ y cada publicación en la página tiene un tamaño entre 50 y $70 \mathrm{~KB}$, debido a que las imágenes antes de ser publicadas deben ser reducidas en tamaño, máximo de 300 × 250 pixeles. El caso más crítico es cuando una publicación requiere de $70 \mathrm{~KB}$.

Con esta información se calcula la capacidad de elementos de red:

$$
N=\frac{250 \mathrm{KBps}}{70 \mathrm{~KB}} \approx 3.6
$$

Se aproxima este valor a $\mathrm{N}=4$

Este sistema se diseña para una Probabilidad de Bloqueo (PB) del 5\%.

Entonces para $\mathrm{N}=4$ y $\mathrm{PB}=0,05$, el tráfico cursado (A) en el sistema con la tabla ErlangBes $A=1,5$ Erlangs.

El tráfico total es

$$
A c=A(1-P B)=1,42 \text { Erlangs }
$$

El sistema está diseñado para soportar un alto tráfico por usuario $(\mathrm{Au})$, aproximadamente de $3 \mathrm{mi}-$ lierlangs, lo que corresponde aproximadamente a 


\section{con-ciencias}

87 publicaciones diarias por usuario. Entonces el máximo número de usuarios que puede soportar la página simultáneamente es:

$$
U=\frac{A c}{A u}=\frac{1,42 \text { Erlangs }}{3 m \text { Erlangs }} \approx 475
$$

\subsection{Máximas publicaciones mensuales}

Una de las limitaciones del servidor contratado es que éste permite como máximo hasta 30 Gbytes de transferencia mensual hacia el servidor; teniendo en cuenta esta información y el análisis de tráfico se puede estimar cuántas publicaciones mensuales se realizan en la página:

$$
\text { No. Publicaciones }=\frac{30 \text { Gbytes }}{70 \text { Kbytes }} \approx 428571
$$

\section{Metodología}

En este apartado se dan a conocer los requerimientos técnicos y la metodología de diseño utilizada en el desarrollo de la plataforma de marketing electrónico.

\subsubsection{Diagrama de clases}

Un diagrama de clases es un tipo de diagrama estático que describe la estructura de un sistema mostrando sus clases, atributos y las relaciones entre ellos. Los diagramas de clases son utilizados durante el proceso de análisis y de diseño de los sistemas, donde se crea el diseño conceptual de la información que se maneja en el sistema y los componentes que se encargan del funcionamiento y la relación entre uno y otro. En la Figura 1 se describe el diagrama de clases de la página desarrollada en donde se pueden encontrar las diferentes clases y atributos que intervienen en el diseño de la página web. Como clase principal se encuentra "Sitio Web Mi Mercado" y de ésta se derivan clases como "usuarios", "componentes", "módulos", "plugin", "idiomas" y "templates".

Se establecen seis clases que interactúan con el Front (página visualizada por el usuario final) y el Back (Espacio de gestión administrativa), en cada una de ellas existen atributos y operaciones públicas y privadas.

\subsection{Modelado UML}

UML (Lenguaje Unificado de Modelado) se puede usar para modelar distintos tipos de sistemas: software, hardware y organizaciones del mundo real. UML ofrece nueve diagramas entre los cuales se encuentran los modelos estáticos o modelos de estructura y los modelos dinámicos o de interacción. Para el modelo estructural se especifica el diagrama de clases dado que se ajusta a las características de la programación orientada a objetos y en el modelo de interacción se describe el modelo de diagrama de secuencias que especifica el comportamiento dinámico entre la web y los usuarios [5]. 


\section{con-ciencias}

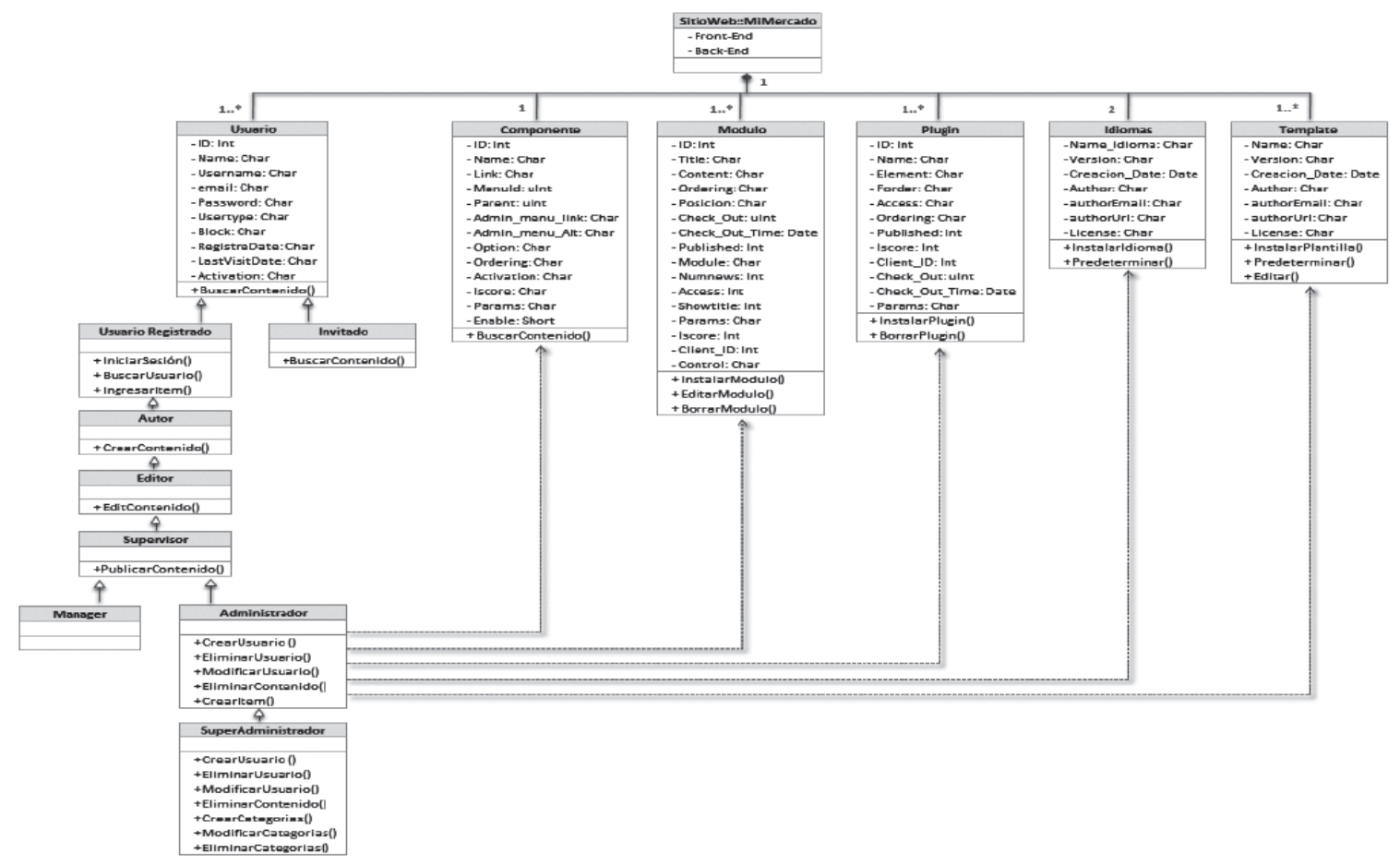

Figura 1. Diagrama de clases utilizado en el diseño de la plataforma de marketing electrónico.

\subsubsection{Diagrama de secuencias}

Para describir el comportamiento de la página sobre el flujo de control y datos entre los elementos del sistema modelado, como diagrama de interacción seleccionado, se usa el diagrama de secuencias, ya que éste contiene detalles de implementación del escenario, incluyendo los objetos y clases que se usan para implementar el escenario y los mensajes intercambiados entre los objetos. El primer diagrama de secuencia ilustra específicamente el proceso de venta, en donde se observa cómo el vendedor interactúa con los diferentes objetos de la página web y cómo, luego de un proceso de DNS (Sistema de Nombres de dominio), accede al código PHP (Preprocesador de Hipertexto) para acceder al sitio [6], posteriormente realiza la solicitud de registro para la creación del usuario sobre la base de datos, durante este proceso se realiza una autenticación del e-mail registrado por el nuevo usuario. Luego de la confirmación del correo registrado, el usuario se activa sobre la base de datos y tiene los privilegios necesarios para realizar la publicación deseada, como se observa en la Figura 2.

En la Figura 2 se presenta el proceso de registro realizado por el administrador de la aplicación de los nuevos usuarios y de los productos. En este proceso el administrador cuenta con una herramienta para manipular la base de datos (Backend) que facilita y agiliza las tareas de administración. 


\section{con-ciencias}
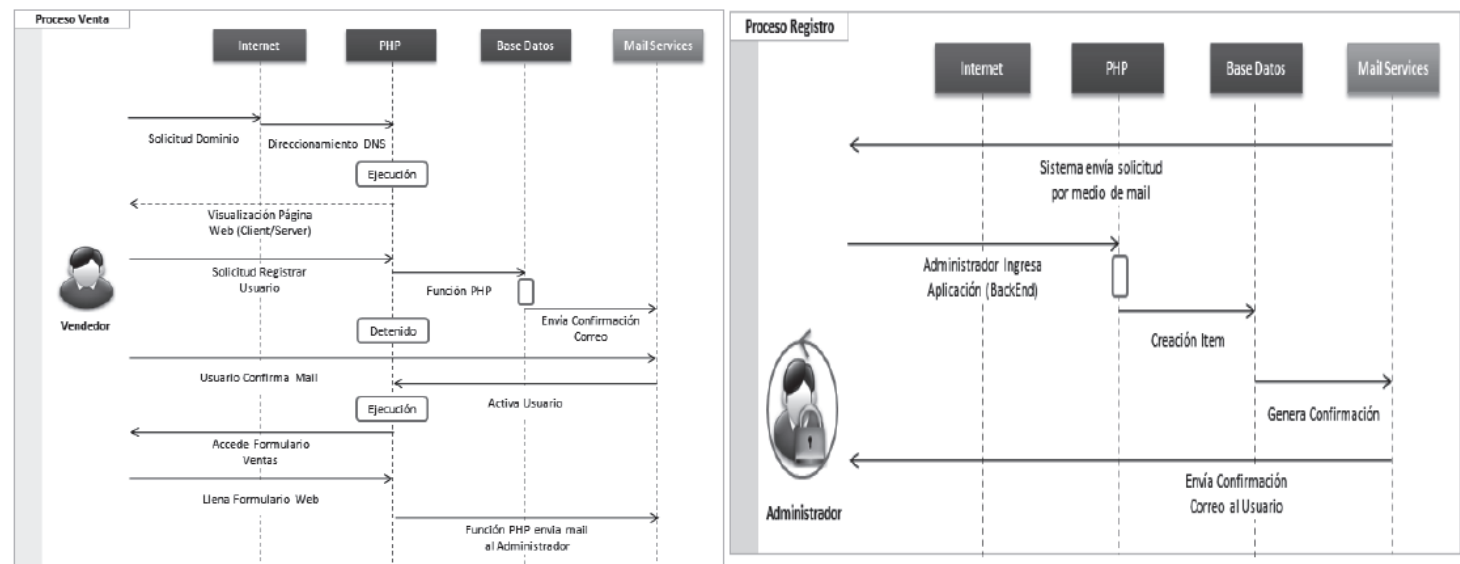

Figura 2. Diagrama UML en secuencias para el proceso de publicación y registro utilizado en el diseño de la plataforma de marketing electrónico.

En la Figura 3 se da a conocer el diagrama de secuencias que describe el proceso de compra, se observa la interacción que hay entre el sistema y el usuario en la compra de un artículo publicado con anterioridad. Primero, el comprador potencial ingresa a la aplicación a través de Internet y busca el artículo de su interés, en este proceso el usuario interactúa tanto con el código PHP como con la base de datos, mientras hace las consultas sobre los diferentes artículos contenidos; luego de que el usuario determina qué artículo desea comprar, puede contar con la información de contacto del usuario que realizó la publicación para acordar la venta del producto.

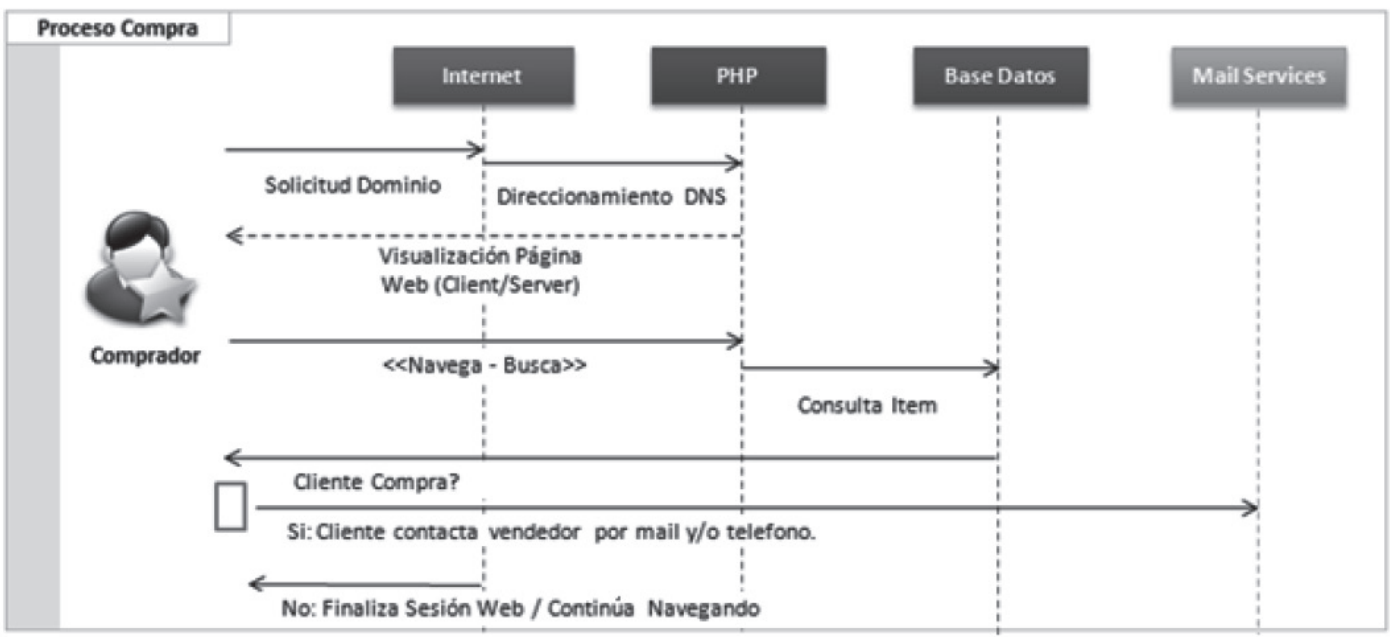

Figura 3. Diagrama UML en secuencias para el proceso de compra utilizado en el diseño de la plataforma de marketing electrónico. 


\section{con-ciencias}

\section{Estructura funcional de la plataforma}

Este mapa permite visualizar la arquitectura de la plataforma piloto de marketing electrónico denominada
MiMercado, desarrollada sobre el gestor de contenidos Joomla 1.5 [7], y que utiliza PHP y una base de datos MySQL [8], como se observa en la Figura 4.

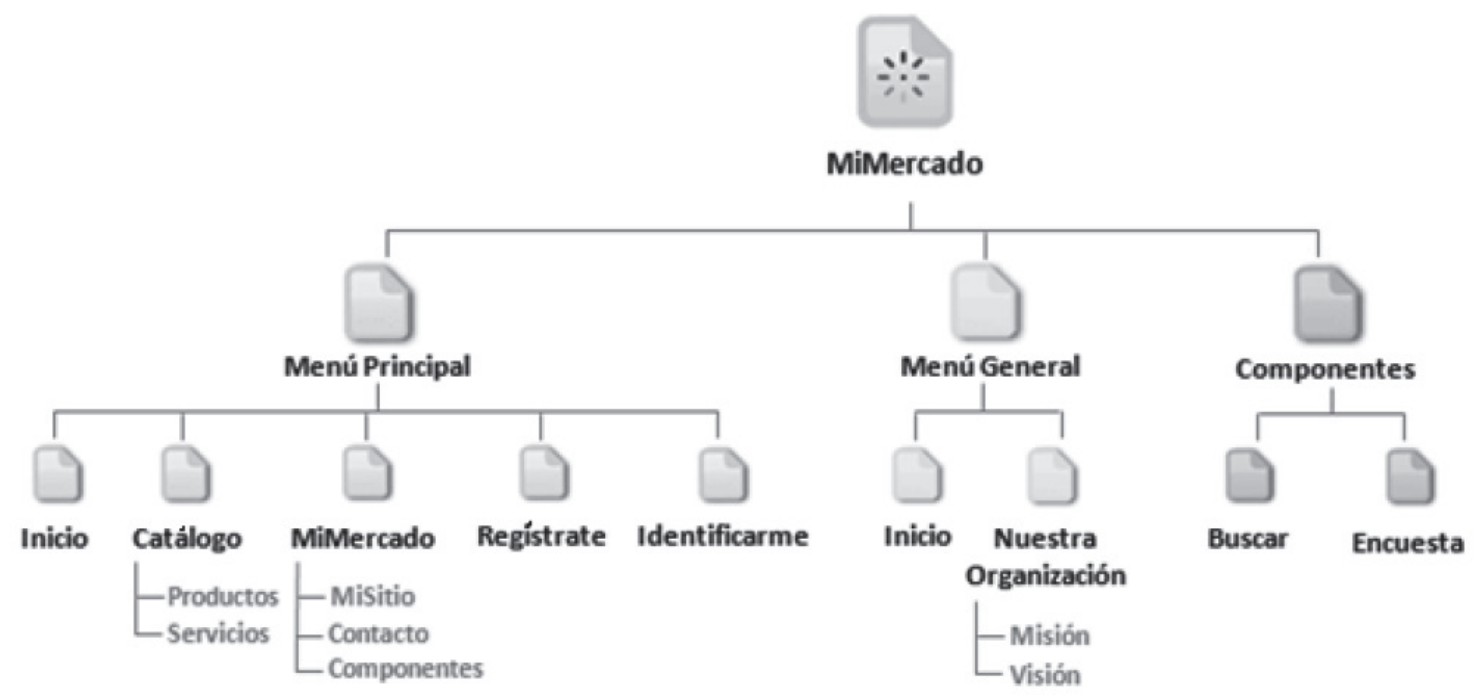

Figura 4. Estructura funcional de la plataforma de marketing electrónico.

\subsection{Diseño y desarrollo de pantallas de la plataforma}

La plataforma está compuesta de dos parte fundamentales: la cabecera (Figura 5) y el cuerpo de la página. A continuación se explica cada una.
En el cuadro 1 se explican los componentes de la cabecera de la plataforma de marketing electrónico numerados en la Figura 5.

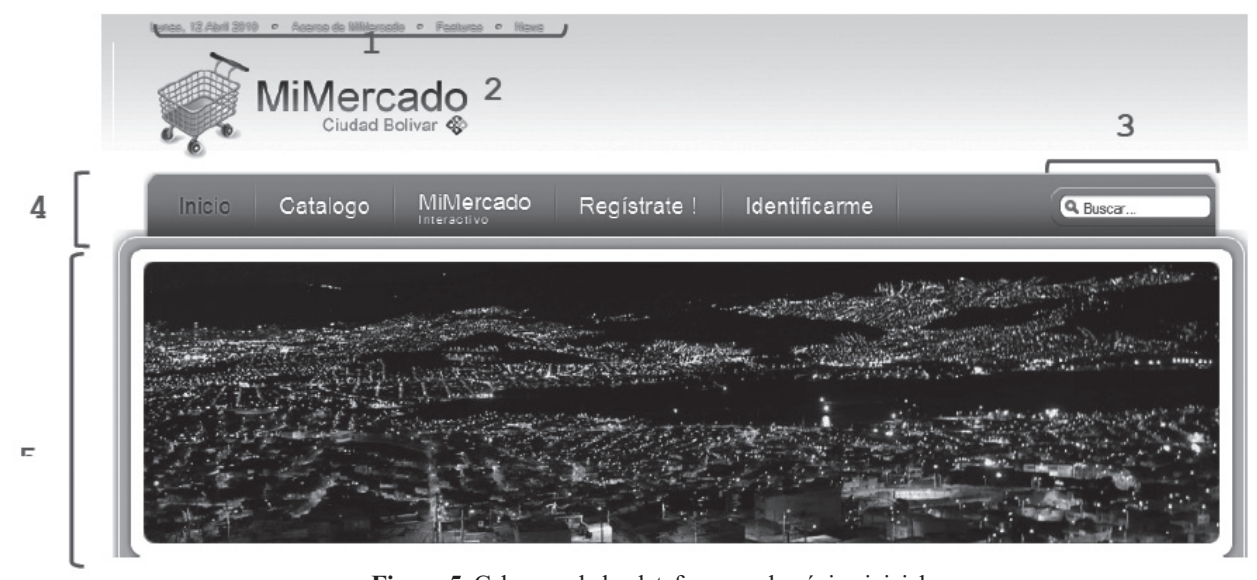

Figura 5. Cabecera de la plataforma en la página inicial. 


\section{con-ciencias}

Tabla 1. Componentes de la cabecera diseñada para la plataforma de marketing electrónico.

\begin{tabular}{|c|c|c|c|}
\hline \# & Elemento & Morfosintaxis & Semántica \\
\hline 1 & Menú user & $\begin{array}{l}\text { Cuatro hipervínculos y fecha del } \\
\text { sistema. }\end{array}$ & $\begin{array}{l}\text { Contiene hipervínculos de información referente a la } \\
\text { página y muestra la fecha actual. }\end{array}$ \\
\hline 2 & Logo general & $\begin{array}{l}\text { Se ubica en la parte superior izquierda } \\
\text { de la página, no posee fondo y el } \\
\text { formato es PNG. }\end{array}$ & $\begin{array}{l}\text { Contiene vínculo al inicio de la página, cuando se pasa } \\
\text { el cursor por el espacio genera un comentario de ayuda } \\
\text { indicando la función del hipervínculo. }\end{array}$ \\
\hline 3 & Buscador & $\begin{array}{l}\text { Cuadro de texto con contenido infor- } \\
\text { mativo y logo. }\end{array}$ & $\begin{array}{l}\text { Función Ajax que busca contenido de la página. } \\
\text { Cuando el usuario marca la casilla, desparece el texto } \\
\text { predictivo y cambia de color el fondo. }\end{array}$ \\
\hline 4 & Menú principal & $\begin{array}{l}\text { Espacios con fondo degrade naranja, } \\
\text { color blanco. }\end{array}$ & $\begin{array}{l}\text { Menú desplegable por medio de Javascript que permite } \\
\text { visualizar hipervínculos. }\end{array}$ \\
\hline 5 & Carrusel imágenes & $\begin{array}{l}\text { Espacio de } 240 \times 720 \text { pixeles que } \\
\text { permite reflejar imágenes. }\end{array}$ & $\begin{array}{l}\text { Componente JScript que cambia la imagen como un } \\
\text { carrusel con un tiempo de } 30 \text { segundos entre transición. }\end{array}$ \\
\hline
\end{tabular}

En la Figura 6 se describe el cuerpo de la plataforma.

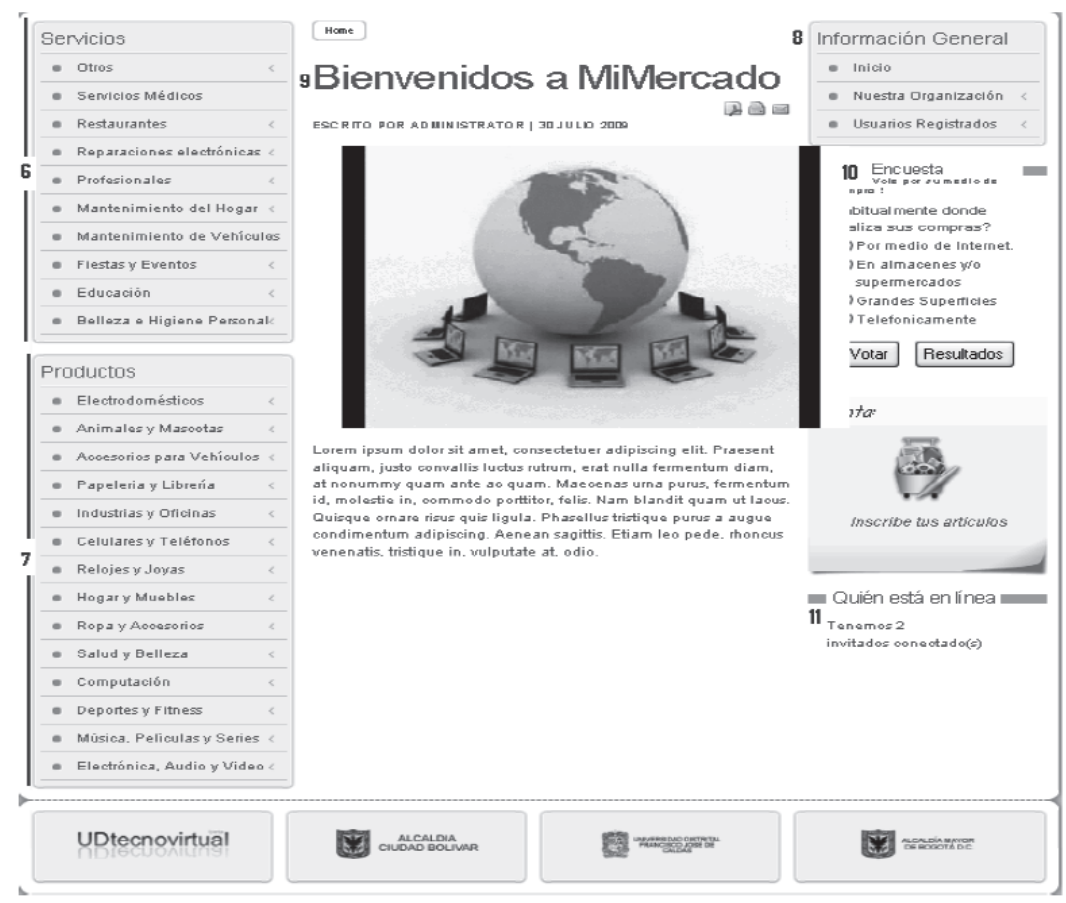

Figura 6. Cuerpo de la plataforma en la página inicial.

Diseño e implementación de una plataforma piloto de marketing electrónico para el desarrollo de aplicaciones TICs en la comunidad de Ciudad Bolívar Luis F. Pedraza / Richard Ramírez Garcia / Óscar Editson Hernández 


\section{con-ciencias}

Tabla 2. Componentes del cuerpo para la plataforma de marketing electrónico.

\begin{tabular}{|c|c|c|c|}
\hline \# & Elemento & Morfosintaxis & Semántica \\
\hline 6 & Catálogo: servicios. & $\begin{array}{l}10 \text { subcategorías que poseen hiper- } \\
\text { vínculos. }\end{array}$ & $\begin{array}{l}\text { Contiene hipervínculos a las subcategorías de ser- } \\
\text { vicios. }\end{array}$ \\
\hline 7 & Catalogo: Productos. & $\begin{array}{l}10 \text { subcategorías que poseen hiper- } \\
\text { vínculos. }\end{array}$ & $\begin{array}{l}\text { Contiene hipervínculos a las subcategorías de Pro- } \\
\text { ductos. }\end{array}$ \\
\hline 8 & Menú general. & Menú tipo acordeón. & $\begin{array}{l}\text { Función JScript que muestra los submenús en forma de } \\
\text { acordeón, cerrándose y abriéndose cuando el usuario } \\
\text { genera un click. }\end{array}$ \\
\hline 9 & Artículo principal. & $\begin{array}{l}\text { Texto prediseñado que se puede } \\
\text { formar utilizando hojas de estilo en } \\
\text { cascada. }\end{array}$ & $\begin{array}{l}\text { Se elige desde el BackEnd el artículo principal para } \\
\text { ubicar en la página. }\end{array}$ \\
\hline 10 & Encuesta. & $\begin{array}{l}\text { Contiene logo, pregunta y posee } 4 \\
\text { respuestas. ( } 2 \text { Botones) }\end{array}$ & $\begin{array}{l}\text { Módulo propio de Joomla que permite realizar en- } \\
\text { cuestas y cuantificarlas, limita la votación desde el } \\
\text { mismo equipo. }\end{array}$ \\
\hline 11 & $\begin{array}{l}\text { Módulo Quién está } \\
\text { en línea. }\end{array}$ & $\begin{array}{l}\text { Visualiza en texto los usuarios regis- } \\
\text { trados en la página. }\end{array}$ & $\begin{array}{l}\text { Función PHP que contabiliza los usuarios conectados } \\
\text { en el portal, tanto registrados como visitantes. }\end{array}$ \\
\hline
\end{tabular}

Los componentes correspondientes al cuerpo de la página de la plataforma de marketing electrónico de la figura 6 se explican en el cuadro 2.

\section{Resultados}

Para poder medir el impacto a corto plazo fue necesario realizar una capacitación a 40 de los comerciantes y prestadores de servicios de la comunidad, a través de la cual se quiso mostrar, por medio de una encuesta, el mejoramiento de las condiciones de comercio de los habitantes gracias a la herramienta de marketing electrónico implementada. Las variables que se evaluaron en la encuesta fueron las siguientes:

- Se le preguntó a los comerciantes qué tan fácil era el acceso a la herramienta y un $80 \%$ de los encuestados respondió que era muy fácil,un
$10 \%$ dijo que era medianamente fácil y un $10 \%$ afirmó que era difícil, lo cual confirma la sencillez del diseño que se eligió para la interactividad. De igual manera, se preguntó a los comerciantes si creían que el aplicativo podía incrementar las ventas en su negocio y se obtuvieron los siguientes resultados:

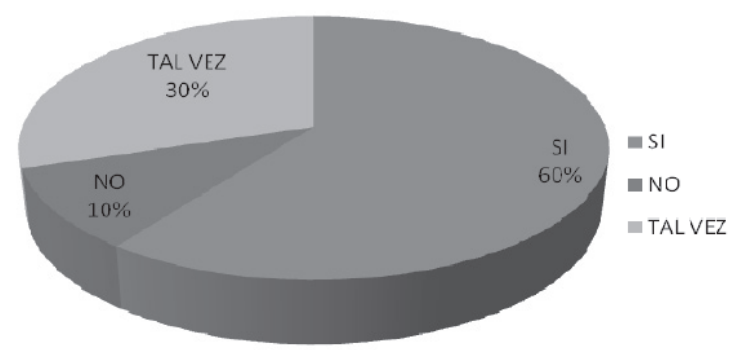

Figura 7. Respuestas porcentuales a la pregunta ¿Creen que la plataforma puede mejorar las ventas en su negocio? 


\section{con-ciencias}

Se preguntó a los comerciantes cómo creían que sería el impacto de la plataforma en su negocio, localidad o barrio. El 70\% de las personas consideraron que este impacto podía er positivo.

Las respuestas a la pregunta: ¿Cómo cree que va a ser el impacto de su negocio para el mercado ajeno a su barrio o localidad?, se muestran en la Figura 8.

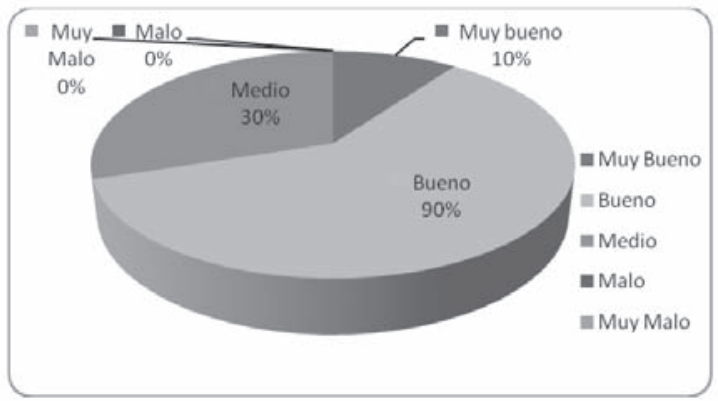

Figura 8. Respuestas porcentuales a la pregunta ¿Cómo cree que va a ser el impacto de su negocio para el mercado ajeno a su barrio o localidad?

Después de la capacitación realizada, el $60 \%$ de los comerciantes consideraron que se sienten capaces de interactuar con la página y el $40 \%$ dice que tal vez; sin embargo, expresaron que en caso de sentirse inseguros se apoyarían en el tutorial que posee el aplicativo.

La totalidad de las personas encuestadas no tenían publicidad de su negocio en Internet y consideraban que la plataforma era una buena alternativa para incorporar su negocio en el mercado global.

\section{Conclusiones}

El aplicativo diseñado permite a las PYMES y a los trabajadores independientes ofrecer productos y servicios, generando de una manera interactiva y rápida un mayor mercadeo, el aplicativo se convierte entonces en una herramienta que contrarresta el desempleo en la localidad. Por otra parte, los comerciantes consideran la plataforma como una herramienta útil de mercadeo, debido a que a través de Internet existen nuevos clientes potenciales.

Gran parte de la economía de la localidad está soportada sobre PYMES, las cuales constituyen una fuente de ingresos diarios para cientos de familias. Éstas fabrican productos de calidad, pero poseen grandes deficiencias en sus áreas administrativas y comerciales que tienen como consecuencia la pérdida de participación en el mercado, de oportunidades de crecer y de dar a conocer sus productos a una población de compradores más grande y diversa. Por otra parte, una barrera que impide el crecimiento económico de estas empresas es que sus principales clientes también tienen bajos ingresos, lo cual obliga a vender con márgenes de ganancia mínimos.

Actualmente, en las PYMES de la localidad predomina la no presencia de computadores y el desconocimiento de sus potencialidades, lo que implica un atraso tecnológico que les impide a los negociantes aumentar la competitividad. $\mathrm{La}$ generación de un mayor volumen de ventas que incremente los ingresos y que mejore la calidad de vida es una preocupación de la localidad. Para una PYME la comercialización implica el desarrollo de procesos logísticos y de distribución o la asistencia de intermediarios. Por lo tanto, el comercio electrónico es una herramienta ideal para mostrar masivamente los productos e impulsar el fortalecimiento de estas empresas, teniendo así un canal alternativo de comercialización.

Una de la principales limitaciones de este proyecto es la falta de recursos económicos para respaldar una campaña de difusión masiva de la plataforma en la localidad, para esto se propone una estrategia de difusión paulatina que aproveche y se apoye de otras iniciativas paralelas como la de los "Portales interactivos de la ETB (Empresa de Telecomunicaciones de Bogotá)" ubicados en la localidad.

Finalmente, se recomienda medir el impacto de la herramienta a mediano y largo plazo para analizar las posibles mejoras. 


\section{con-ciencias}

\section{Referencias bibliográficas}

[1] G. Mancilla, Medición de la situación de acceso, uso y apropiación de las TICS por parte de hogares de la localidad de Ciudad Bolivar. Bogotá Colombia: documento base proyecto Ciudad Bolívar Localidad Digital, febrero 2009.

[2] R. Guerrero, L. Rivas, "Comercio Electrónico en México: propuesta de un modelo conceptual aplicado a las PYMES". México: Revista Internacional de Ciencias Sociales y Humanidades, vol.15, pp. 79-116, 2005.

[3] S. Rubino, "Red gealc cinco años de apoyo al e-gobierno en América Latina y El Caribe", Estados Unidos: monografía financiada por el Banco Interamericano de Desarrollo, 2010.

[4] R. Camerano, Teoría de Colas: Aplicación a las Telecomunicaciones, Bogotá Colombia: Universidad Distrital Francisco José De Caldas, primera edición, 1997.
[5] A. García, E. Soria, Desarrollo de un sistema de gestión de contenidos de ayuda en web, Madrid España: Universidad Carlos III de Madrid, primera edición, 2006.

[6] R. Lerdorf, K. Tatroe, Programming PHP, Estados Unidos: O'Reilly, segunda edición, 2006.

[7] B. North, Joomla! 1.5 a User's Guide, Estados Unidos: Prentice Hall, segunda edición, 2009.

[8] M. Glass, Y. Scouarnec, E. Naramore, G. Mailer, J. Stolz, J. Gerner, Beginning PHP, Apache, MySQL Web Development, Estados Unidos: Wiley Publishing, 2004. 